\title{
Examining the Formation of Integrative Readiness of Pre-Service Teachers to work in Inclusive Classrooms in Ukraine
}

\author{
Olena M. Yashchuk ${ }^{1}$, Serhii M. Yashchuk ${ }^{2}$, Halyna I. Kobernyk ${ }^{1}$, Serhii A. Kotlovyi ${ }^{3} \&$ Iryna O. Biletska $^{4}$ \\ ${ }^{1}$ Department of Theory of Primary Education, Primary Education Faculty, Pavlo Tychyna Uman State Pedagogical \\ University, Uman, Ukraine \\ ${ }^{2}$ Department of Professional Education and Technology by Profile, Faculty of Physical Education, Pavlo Tychyna \\ Uman State Pedagogical University, Uman, Ukraine \\ ${ }^{3}$ Department of Social Technologies, Social Psychology Faculty, Ivan Franko Zhytomyr State University, Zhytomyr, \\ Ukraine \\ ${ }^{4}$ Department of Foreign Languages Theory and Practice, Faculty of Foreign Languages, Pavlo Tychyna Uman State \\ Pedagogical University, Uman, Ukraine \\ Correspondence: Olena M. Yashchuk, Department of Theory of Primary Education, Primary Education Faculty, Pavlo \\ Tychyna Uman State Pedagogical University, 2, Sadova str., Uman, 20300, Ukraine.
}

Received: July 21, 2020

Accepted: July 28, 2020

Online Published: August 3, 2020

doi:10.5430/ijhe.v9n5p208

URL: https://doi.org/10.5430/ijhe.v9n5p208

\begin{abstract}
The article addresses potential issues surrounding the development of the integrative readiness of pre-service teachers to work in inclusive classrooms in Ukraine. Integrative readiness is an open, dynamic, synergistic system functioning of cognitive, motivational, affective, and selective processes which is developed through the purposeful training of future teachers for work in inclusive, which is included in the educational social environment as a tool for acquiring productive knowledge, forming integrative skills. The structure of integrative readiness includes personality orientation; ability to perform their duties, professional competences; productive knowledge that the student receives from environmental information based on personal prior knowledge, skills, personal and professional qualities, and integrative skills that demonstrate the ability of an individual to make independent decisions and appropriate actions in unpredictable new situations. The levels of integrative readiness were investigated, covering the following interrelated stages: theoretical analysis, synthesis, comparison; modelling and technological design; generalization; observational; pedagogical experiment. A study was conducted. The research involved 285 pre-service teachers from the Ternopil Volodymyr Hnatiuk National Pedagogical University, enrolled in the Speciality 016: Special Education unit. A structural model of the formation of integrative readiness of future teachers for professional activity was developed-which consisting of the following blocks: target, content and procedural, and resultant. The research finding reported that the effectiveness of corrective, developmental, and educational work in the educational inclusive space largely depended upon the quality of training of the pre-service teacher, and the use of active and interactive training.
\end{abstract}

Keywords: integrative readiness, inclusive education, children with special educational needs problems, responsibility, structural model, interactive methods

\section{Introduction}

\subsection{Topicality}

The profound socio-economic and political transformations that took place in the $20^{\text {th- }} 21^{\text {st }}$ centuries for children with special needs and the realization of their right to education, drove significant reforms of the Ukraine national education system. Analysing the National Strategy for the Development of Education in Ukraine for 2012-2021, the Concept of Development of Inclusive Education of 2010 (Ukraine), the UNESCO Salamanca Statement of 1994 and the UN Convention on the Rights of Persons with Disabilities (2006), it was determined that inclusion is an important link in their country's educational field.

The increasing number of children with special educational needs and the introduction of inclusive education in the Ukrainian education system required an increase in the number of competent and effective educators in the field of 
special education. From this perspective, improving the training of qualified teachers for the inclusive classroom is urgent. In Ukraine, introducing inclusive reforms into general educational institutions is complex, as this requires recognising the barriers to general education, namely: high numbers and insufficient levels of competent academics in higher educational institutions to teach inclusive education; a lack of a united understanding of the issues of implementing of inclusive education in different educational structures; and the absence of an individual-focused priority and value in modern general education (Demchenko, 2015).

The importance of inclusive education teachers of great importance as they influence the process of social adaptation of children with special needs, the formation of their life goals, the ability to self-development, and promote self-realization in all spheres of activity (Demchenko, 2016).

A comprehensively trained and developed teacher must be competitive in today's and future job markets, successfully addressing special education issues, focusing on communication and interaction with different categories of children. Therefore, future teachers should be adequately trained to work with children with special needs.

Due to the increasing volume of information in higher educational institutions, academic teaching staff cannot provide the pre-service teacher with all the professional knowledge they need, but in doing so, they may provide generalized productive knowledge that may help develop professional thinking (Nikolić Vučinić et. al., 2019). One approach to the educational process is the integration process, which creates the basis for developing the skills to solve professional tasks in future activities (Kozlovsky, 2018).

To achieve integrated professional training, it is necessary to properly and organize the presentation of the content and its structuring, for example in the form of modules. Thus, the use of generalized, integrative approaches is relevant in preparing future teachers for work under the conditions of inclusive learning.

\subsection{Literature Review}

The literature review found that the student teachers' readiness can be associated with the integrated functioning of cognitive, motivational, affective, and selective processes (Skočić Mihić, Lončarić \& Bažon, 2019). Additionally, the education process will be effective because, according to Martins \& Chacon (2020), the motivation of the students results from their achievements in cognition, and then the positive thoughts from the above will positively influence their emotional state. The integrated readiness is also interpreted as the teachers' ability to assess their effectiveness in motivating the students, in encouraging and persuading them to succeed in their studies (Skočić Mihić, Lončarić \& Bažon, 2019). Thus, it is crucial to train the student teachers' self-efficacy for the inclusive practices seen as a component of the psychological readiness to work in the inclusive preschool environment (Ahsan, Deppeler \& Sharma, 2013; Aspelin \& Jonsson, 2019). However, the currently used training system of the student teachers who are trained to work in an inclusive environment is dispersed and disintegrated. It lacks opportunities to gain experience in safe conditions and before the students graduate and are employed.

The professional training of future teachers for work with children with special needs at the present stage is mainly carried out in the process of professional education. To become a professional teacher to work under the conditions of inclusive education in the modern economic, and social conditions of Ukraine. It is important to create and develop productive knowledge, integrative skills, and practical skills that is, components of professional competence, communication, autonomy, and responsibility, in professional training at higher educational institutions (Martynchuk, 2019).

The future teacher's competence in teaching children with special needs is the basis for one of the professional fulfillment of their duties. Effective teachers apply their knowledge and skills to organize and carry out educational activities with different categories of children. They help children to adapt to society, create the resources they need, ensure interaction between people, or between a person and their environment. A teachers' knowledge and skills necessary to prepare, adopt and reflect assessment procedures - formal or informal, formative, or summary - shall comply with assessment or diagnostic competencies (Herppich et al., 2018).

The competencies of future teachers are is formed not only by the knowledge and proven skills and abilities, but also by the personality position of a specialist, the analysis of experience at the level of theory, understanding of different approaches to the socialization of children with special educational issues, and the choice of methods (Skočić Mihić, Lončarić \& Bažon, 2019). The technological and pedagogical competencies of teachers was a major factor influencing both their practical field and their integration into education in general (Suárez-Rodríguez, Almerich, Orellana \& Díaz-García, 2018), with technological competences affecting pedagogical competences. 
Promoting educational competence in pre-service teachers is an important responsibility of higher educational institutions (Aspelin \& Jonsson, 2019), and involves mastering andragogical principles and integrating the components of various technologies into learning activities (Dehon, Robertson, Barnard, Gunalda, \& Puskarich, 2019). Thus, competence shapes the readiness of a future teacher to work in an inclusive educational environment, enables them to fulfil professional roles in their teaching activities, and contributes to the creation of mechanisms for the socialization of children with special educational needs (Skočić Mihić, Lončarić, \& Bažon, 2019). Training of future teachers for work with children with special needs can be schematically represented in the form of the following didactic chain of formation of professional readiness, which is shown in Figure 1.

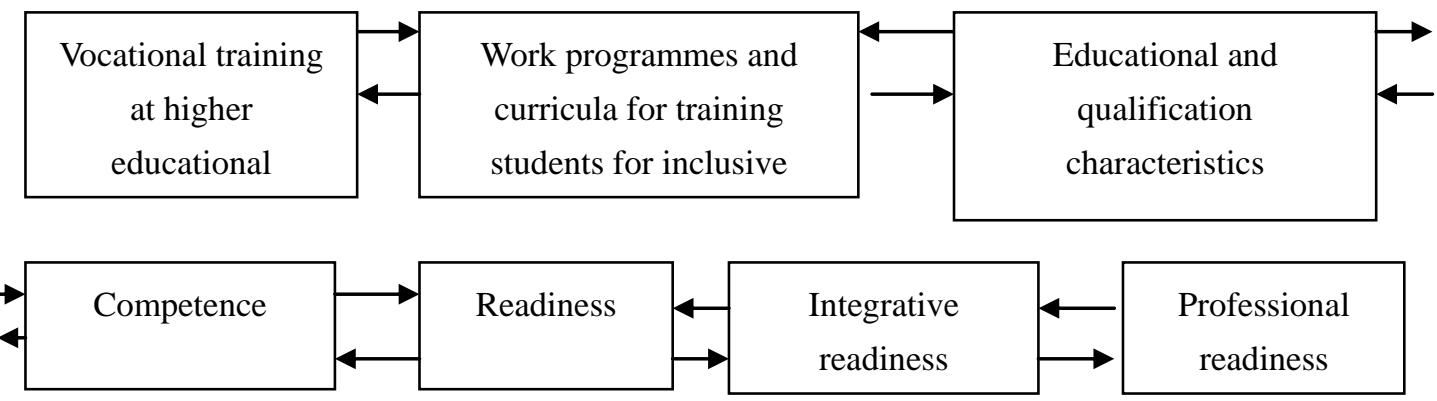

Figure 1. Didactic chain of formation of professional readiness (adopted from Martynchuk, 2019)

Thus, an important aspect of appropriate professional training of teaching staff is the formation of integrative readiness for professional activity.

When analysing the concept of "readiness for professional activity", the process of forming readiness for professional activity could be purposefully managed, provided an appropriately built model of the educational process, created appropriate psychological and pedagogical conditions, and the use of pedagogically appropriate technologies (Martynchuk, 2019).

There is a current need to form the readiness for future professional activity of students of the 1st and 2nd years of study at higher educational institutions, as it is during this period that the foundations of readiness for future work are laid. This stage is especially important for the professional self-determination of students, and for them to realize themselves as future specialists. Therefore, it is necessary to help students of the 1st year of study to understand and realize the correctness of their professional choice, to direct students to the formation of personal and professional qualities that will help them to become competent teachers.

The successful formation of pre-service teachers' readiness for work in the inclusive classroom depends on certain conditions and students' internal awareness of the goals of the teaching and their attitude towards it (Skočić Mihić, Lončarić \& Bažon, 2019). This state of readiness is largely determined by the persistent psychological characteristics that are inherent in a particular person (Hobfoll, Halbesleben, Neveu \& Westman, 2018).

When analysing the pedagogical literature, the attention was focused on the professional subjectivity (readiness) of a future teacher as an important professional quality and specification of the manifestations of professional subjectivity (awareness of the essence, requirements, and specifics of professional activity and their perception; professional self-concept; defining the profession of "teacher" as the main way of self-actualization and clarification of its essential characteristics such as activity, productivity, integrity, integrality, and consistency of subjective qualities and manifestations of teachers in professional activity, realization, and perception of their social and professional subjectivity (Kozlovsky, 2018).

The future teacher's professional activity in the field of inclusive education meets the basic criteria of professional subjectivity (Skočić Mihić, Lončarić \& Bažon, 2019), and thus the task is to form an integrative readiness as the foundation of a teacher's professional subjectivity.

The above seems the reason for the feasibility of this study which attempted to gain new experience through the use of the specifically organised training programme aimed at fostering student teachers' readiness for working in preschool inclusive settings.

\section{Materials and Methods}

The study was a quasi-experimental study that used mixed-methods to measure the variables. The variables for the study were the students' efficacy for inclusive practices, students' academic self-efficacy, communicative and organizational efficacy, emotional reaction to the influence of environmental stimuli, and the anxiety level. The 
pedagogical study of the formation of integrative readiness of pre-service teachers for work in the inclusive classroom was prolonged and covered the following interrelated stages. First, theoretical analysis, synthesis, the comparison was performed for the conceptualization of philosophical, psychological, and pedagogical scientific literature, the study of regulatory documents in the field of education. Concurrently, classification and systematization of theoretical and experimental data relating were fulfilled to identify the nature, main manifestations, and characteristics of the future teacher's readiness for work under the conditions of inclusive education. Induction and deduction, comparative analysis of theoretical, empirical, and experimental data were applied to analyse the effectiveness of the application of research methods, modelling of students' educational activity. Second, modelling and technological design were completed to specify the content, psychological and pedagogical conditions, creation of a structural model of formation of integrative readiness of future teachers for work under the conditions of inclusive education. Third, generalization was applied to work out and interpret the theoretical sources on the studied problem, state standards of higher education, educational and qualification characteristics, university documentation (curricula, programs, methodological support complexes), results of students' activities, determination of regularities, formulation of summaries and conclusions. Forth, the observational stage that relied on testing, questioning, pedagogical observation and was intended to determine the levels of development of students' integrative readiness for professional activity, its specific traits, and dynamics of development. The survey was used to identify the motives for the professional formation and determine the characteristics of educational activities of future teachers at higher educational institutions; testing - to study the dynamics of readiness, personal and professional qualities of future teachers. Fifth, the pedagogical experiment was run to test the effectiveness of the proposed psychological and pedagogical conditions of forming integrative readiness of future teachers for work with children with special educational problems.

\subsection{Sampling}

The study involved a population of 285 students (231 females and 54 males aged 20-22) seeking a degree in the Specialty 016: Education for students with special needs at the Ternopil Volodymyr Hnatiuk National Pedagogical University.

\subsection{Instruments}

The Teacher Efficacy for Inclusive Practices Scale (TEIPS) (Martins \& Chacon, 2020) and the survey questionnaire entitled "Awareness of One's Professional Choice", Communicative and Organizational Abilities Questionnaire (COAQ) (Demchenko, 2016), diagnostics of the emotional reaction to the influence of environmental stimuli (Demchenko, 2016); a technique for diagnosing the anxiety level - the Taylor Manifest Anxiety Scale (Demchenko, 2016); Wartegg's "Circles" (Demchenko, 2016) were used to measure the variables. Three experts were hired to validate the questionnaire. The responded to the questions from the questionnaire individually and assessed the clarity, significance, and concreteness of each item. After that, they used a 4-point rating scale (from 1 meaning 'not clear' ('not concrete' or 'not significant') to 4 meaning 'totally clear' ('absolutely concrete' or 'very significant')) to assess every item. The experts' ratings were utilised to calculate the content validity index (CVI) of each item as it was recommended by Rodrigues et al. (2017). The computation was based on the formula below.

$$
\mathrm{CVI}=\frac{\mathrm{n} \text { of raters provided rating scores from } 1 \text { to } 4}{\mathrm{n} \text { of raters in total }}
$$

The item was considered adequate if the average score for the experts' agreement was higher than $3.00(\approx 75 \%)$.

\section{Results}

The important result of the study was the structural model (see Fig. 2) of the formation of integrative readiness of future teachers under the conditions of inclusive education. It integrates and consolidates the process of training teachers for work under the conditions of inclusive education is the formation of their professional and personal qualities, productive knowledge, integrative and practical skills. 


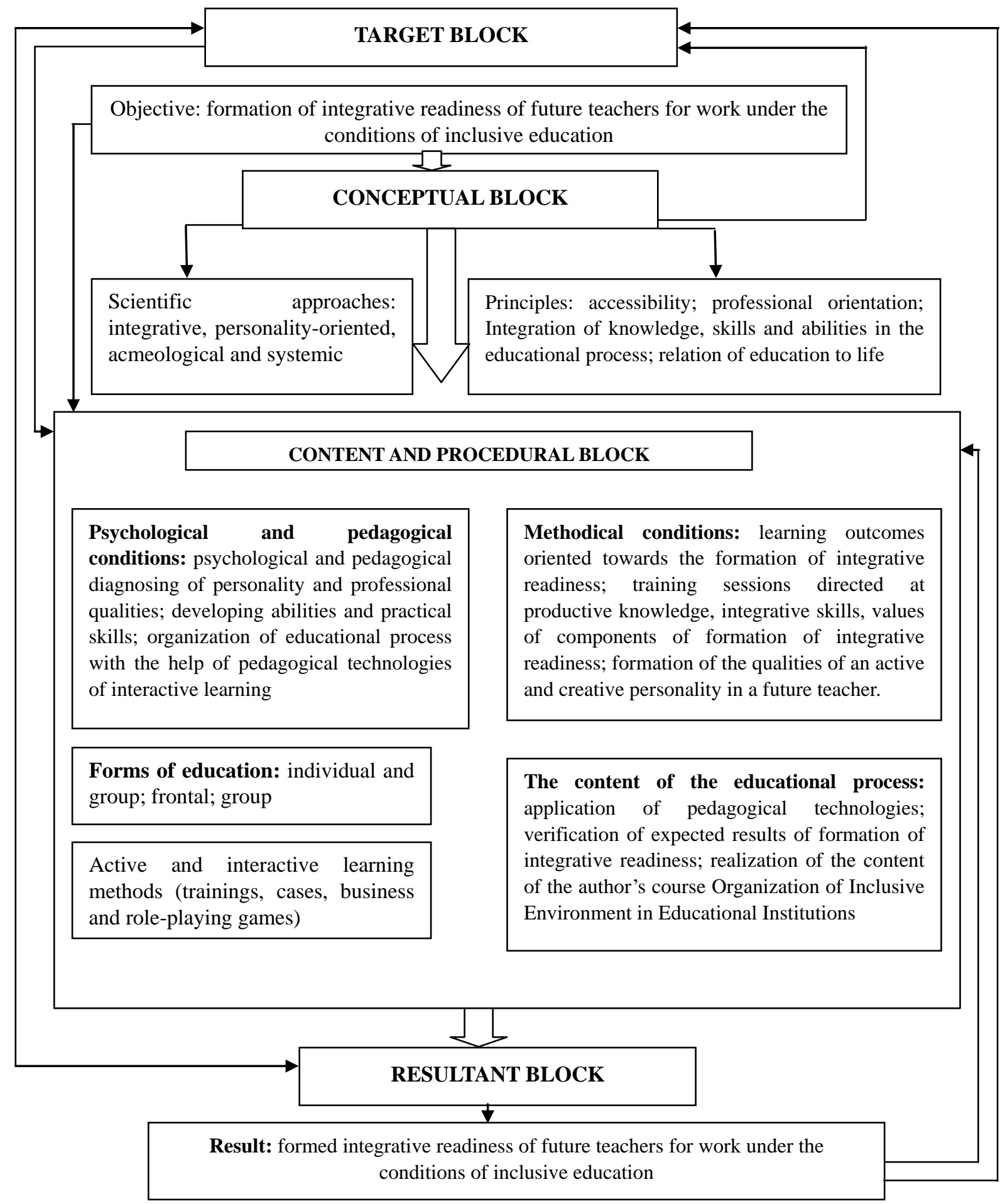

Figure 2. Structural model of the formation of integrative readiness of future teachers under the conditions of inclusive education

Below are the results of different measurements administered before and after the experiment. They prove the effectiveness of the above model in the formation of different dimensions of the pre-service teachers' readiness to work in the inclusive classroom.

\subsection{The Teacher Efficacy for Inclusive Practices Scale}

The TEIPS was administered before and after the intervention. The results of the measurements are presented in Table 1. 
Table 1. The results of the measurements based on the TEIPS before and after the intervention

\begin{tabular}{lcccccc}
\hline \multirow{2}{*}{ Dimension } & \multicolumn{2}{c}{ Median } & \multicolumn{2}{c}{ SD } & \multicolumn{2}{c}{$\begin{array}{c}\text { Probability a Normal } \\
\text { Distribution }\end{array}$} \\
\cline { 2 - 7 } & Before & After & Before & After & Before & After \\
\hline $\begin{array}{l}\text { Inclusion-purpose educational } \\
\text { strategies }\end{array}$ & 3.99 & 4.7 & 1.54 & 1.27 & 0.026 & 0.0027 \\
$\begin{array}{l}\text { Managing students' behaviour } \\
\begin{array}{l}\text { Instructors' awareness and } \\
\text { ability to cooperate }\end{array}\end{array}$ & 2.8 & 4.1 & 2.31 & 1.99 & 0.167 & 0.062 \\
\hline
\end{tabular}

The median scores showed a positive change in all the dimensions on the scale. This proved that the sampled students experienced an improvement in their inclusion-related pedagogical skills in general, and awareness of dealing with students' parents, their family members, and other peers and professionals, in particular.

\subsection{The Survey Questionnaire Entitled "Awareness of One's Professional Choice"}

Q1: What is an educational inclusive space? Twenty-two percent of students said it is a specialized education system aimed at developing a child with disabilities. Forty-six percent of respondents answered that it is an educational process based on the development of a child in general educational institutions. Thirty-two percent of the surveyed indicated that it is an organization of special education, through which the correction of a child's developmental disorders in a properly created environment is realized.

Q2: What difficulties can you expect in the process of organizing work under the conditions of inclusive education? Fifty percent of future teachers indicated insufficient practical experience, inability to communicate with children and their relatives. Twenty-seven percent of students said that there is a lack of technical, methodological support, adequate methodological literature, and adequate facilities for the organization of inclusive education. Twenty-three percent of the respondents indicated the passivity of the administration, educators, the lack of teamwork.

Q3: What teaching tools do you know that help you organize your work in inclusive education? Thirty-nine percent of respondents said that the main tool is literature which presents the theoretical foundations of the organization of inclusive education. Thirty-three percent of students said that it is regular classes and psychological training. Twenty-one percent of students mentioned technical facilities and visualization. Seven percent indicated the exchange of practical experience.

Q4: What are the methods in a higher educational institution that will help in your professional training for work in an inclusive space? Thirty-two percent of students named individual and group consultations, conversations, lectures. Thirty-nine percent of respondents specified solving pedagogical situations, role-playing, and business games. Twenty-nine percent of respondents consider the experience of specialists effective.

Q5: What psychological and pedagogical conditions are most effective in future teachers' professional training? Sixty-six percent of students noted the joint interaction of students, teachers, correctional educators, supervisors, parents. Seventeen percent of future specialists have a practical orientation of their study at higher educational institutions. Fourteen percent of the respondents mentioned methodical and technical support of the correction process. Three percent of students mentioned fundamental theoretical and practical training of future teachers for work under the conditions of inclusive education.

Amongst the negative answers were few that are as follows: the students identified the following problems regarding the future teachers' professional training for work in an inclusive classroom, low motivation to work in inclusive institutions, emotional instability; insufficient logistical support; the lack of comprehensive didactic and practical professional training of future teachers for the organization of work in inclusive classes, the limited content richness of modules of the subjects, etc.

\subsection{Academic Performance: Test Results}

The results in tests and module control assessments are presented in Table 2. The following grades were obtained for students of Specialty 016: Special Education. 
Table 2. Results in Academic Performance

\begin{tabular}{ccccc}
\hline Year of study & $\begin{array}{c}\text { Excellent } \\
(90-100-\text { ECST })\end{array}$ & $\begin{array}{c}\text { Good } \\
(70-89-\text { ECTS })\end{array}$ & $\begin{array}{c}\text { Satisfactory } \\
(60-69-\text { ECTS })\end{array}$ & $\begin{array}{c}\text { Unsatisfactory } \\
(>60 \text { ECTS })\end{array}$ \\
\hline 1 & $16 \%$ & $27 \%$ & $36 \%$ & $21 \%$ \\
2 & $10 \%$ & $35 \%$ & $32 \%$ & $33 \%$ \\
3 & $23 \%$ & $25 \%$ & $41 \%$ & $11 \%$ \\
4 & $21 \%$ & $32 \%$ & $35 \%$ & $12 \%$ \\
\hline
\end{tabular}

3.4 Communicative and Organizational Abilities Questionnaire (COAQ)

As can be seen, the communicative and organizational skills are interconnected; organizational skills help to influence children with special needs; respond quickly in different situations; organize the interaction of children in a particular direction. The results of this study are shown in Figure 3.

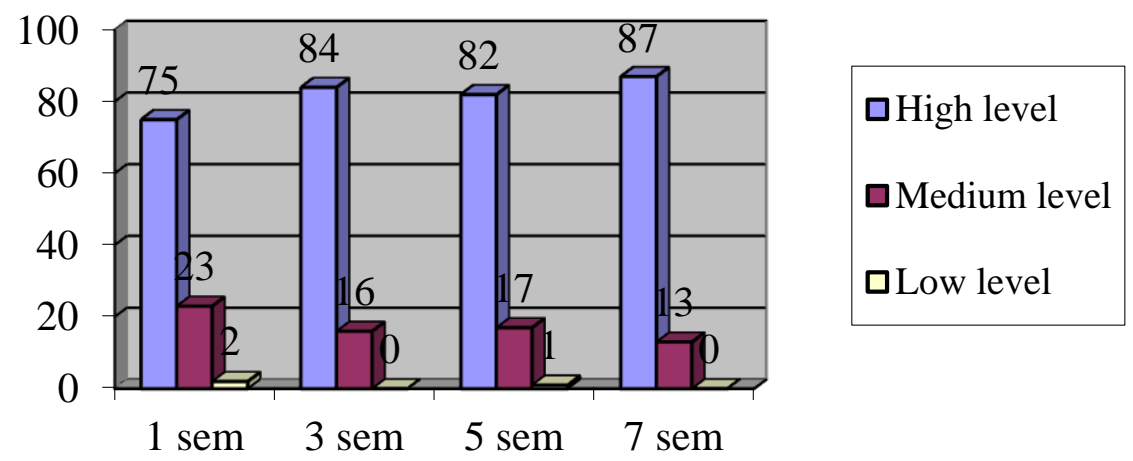

Figure 3. Level of communication and organizational skills of future teachers (\%)

The study of emotional processes is essential for future teachers' work under the conditions of inclusive education. Because emotions affect such areas of personality as volitional, intellectual spheres, and the psyche of a future specialist which influences the activation of the volitional sphere. This agrees with Chetverikova (2017) who stated that the emotions of positive intensity can repeatedly increase the effectiveness of future teachers' professional activities to work under the conditions of inclusive education.

The activity of future teachers is of particular importance, which is carried out in the conditions of a high level of responsibility, unpredictability, and other strong emotional factors. Therefore, professional training should be carried out in such a way as to ensure the formation of the emotional stability of an individual.

Successful training of future teachers is influenced by volitional, intellectual, and emotional spheres. Positive sthenic emotions of adequate intensity contribute to increasing the efficiency of the professional activity of a future specialist. Negative asthenic emotions lead to stress and adversely affect health and performance (Chetverikova, 2017). The results of the study of the influence of types of emotional reaction on environmental stimuli, which was conducted according to the diagnostics of the type of emotional reaction to the influence of environmental stimuli, are shown in Figure 3 .

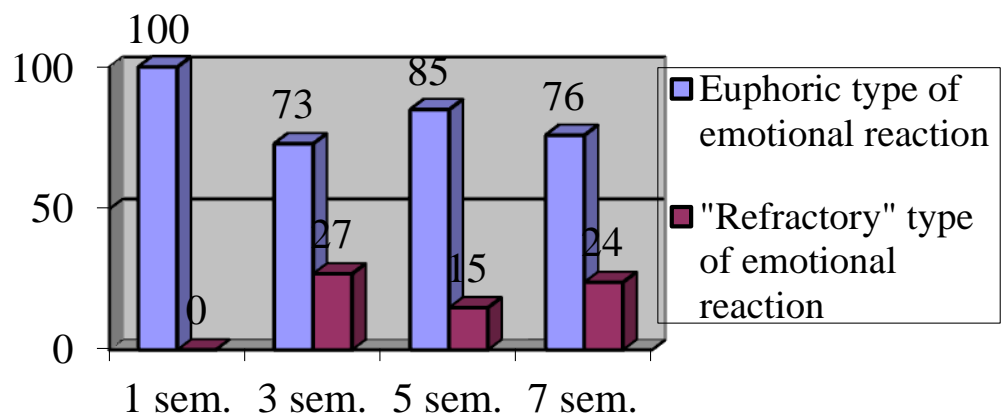

Figure 3. Impact of types of emotional reaction on environmental stimuli (\%) 


\subsection{Diagnostics of the Emotional Reaction to the Influence of Environmental Stimuli}

The results of the study showed that the psychological characteristics of future teachers are marked by emotional and vegetative lability. It begins during the period of study at a higher educational institution, which is accompanied by a change in the stereotype of work (study at school). The students get adapted to this, an increase in the volume of information increased requirements to the adaptive capacity of the body, which may lead to maladaptation in the future.

Personal anxiety was identified through psychological research using Taylor's Manifest Anxiety Scale. The dynamics of changes in the level of general and personal anxiety of future teachers in the process of educational work is presented in Figure 4.

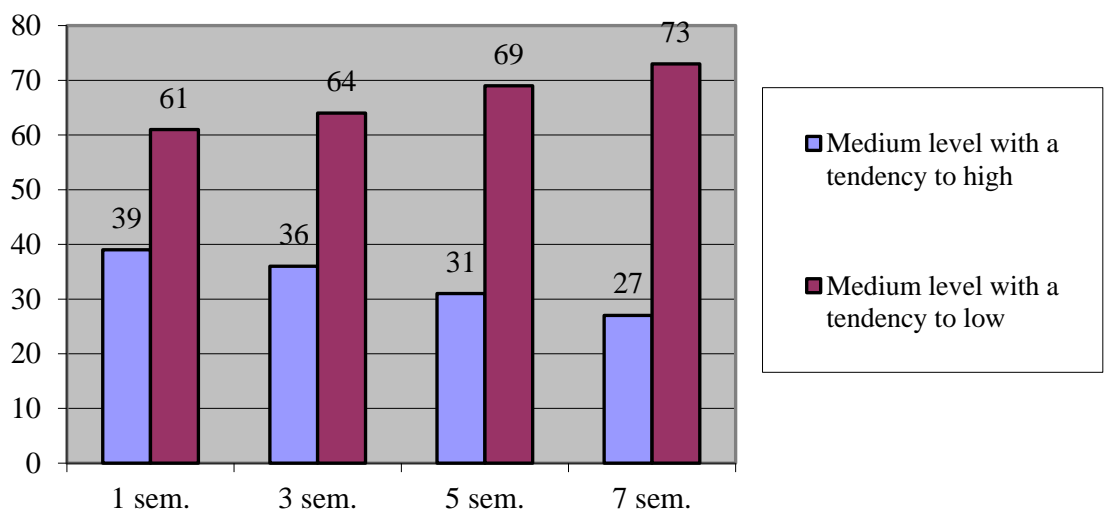

Figure 4. Dynamics of change in the level of general and personal anxiety in future teachers (\%)

Anxiety in the $1^{\text {st }}$ year of study was high in almost half of the students, and with each passing semester, it was decreasing, which could probably indicate that the professional training of students every year helps to form emotional stability in future teachers.

We also considered such a quality of future teachers as creativity, where a high manifestation of creative abilities is usually combined with certain personal qualities. Such personality traits as self-confidence, courage, freedom are not only inherent in creative people but also increase the likelihood of realizing their creative potential.

Considering creative processes characterized by originality, speed, and flexibility of thinking (images are created quickly and have a high switching capacity), we have concluded that they have their peculiarities, which are created during life, activity, and largely determined by learning and education.

The literature reports that there are two sides for creativity in education: structuring an assignment, providing additional information, and evaluating what has been created so far, can be equally important (Kaufman, Beghetto \& Watson, 2016; Kozlovsky, 2018; Skočić Mihić, Lončarić, \& Bažon, 2019).

How can teachers contribute to their pupils' creativity? One approach is summarized and considers creativity as a result of education (Skočić Mihić, Lončarić, \& Bažon, 2019), the second one is formative and aimed at understanding creativity as part of education (Kaufman, Beghetto \& Watson, 2016). According to the first approach, interventions in the process of conducting classes based on theoretical principles of creativity could be applied, and to guide pre- and post-test studies on well-known creative activities such as divergent thinking. The results are analysed statistically to see if there is a significant increase in average creativity scores over time. Preferably, this is an increase compared to the control group. In the second approach, creativity is often analysed qualitatively, because it occurs through social interaction in educational institutions where students and teachers work (together) on creative assignments, such as in the classes of curricular or extracurricular arts, dance, etc. With these two approaches, you can define what creativity is. In the first approach, creativity is seen as a hidden, individual trait that can be "realized" by the tasks of creative thinking that can be positively or negatively affected by the environment. In the second approach, creativity is seen as innate and results from the interaction between students and faculty (Kupers, Lehmann-Wermser, McPherson \& van Geert, 2019; Glaveanu et al., 2019).

Based on the analysis of the views of foreign scholars, who pointed to the significant importance of creativity in the 
teacher's activity, a research was conducted according to the Wartegg's "Circles" test (Chetverikova (2017). The results of creative thinking are shown in Figure 5.

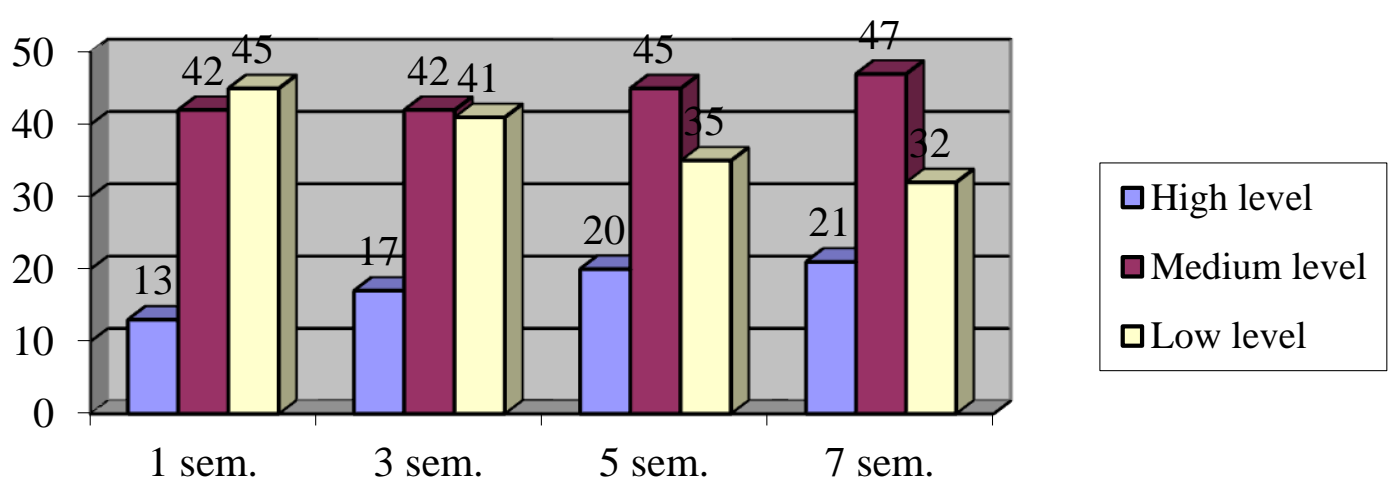

Figure 5. The creativity of thinking of future teachers $(\%)$

According to the results of the study, it was found that a high ability to switch to fast and creative processes was formed in students - future teachers with the help of interactive teaching methods with every year of study.

The professional identification as a dynamic structure that develops nonlinearly and unevenly was considered and is determined by the person's desire for integrity, which includes motivation for professional activity.

It is the motivation that is the main factor that determines the development of the creative activity of an individual. According to the results of the survey conducted with the use of Motivation to Study at Higher Educational Institution method, the following data were obtained (See Table 3).

Table 3. The results of measurements of Motivation to Study at Higher Educational Institution

\begin{tabular}{cccc}
\hline \multirow{2}{*}{ Year of study } & \multicolumn{3}{c}{ Level } \\
\cline { 2 - 4 } & High & Medium & Low \\
\hline 1 & $17 \%$ & $53 \%$ & $25 \%$ \\
2 & $20 \%$ & $55 \%$ & $18 \%$ \\
3 & $25 \%$ & $57 \%$ & $20 \%$ \\
4 & $23 \%$ & $57 \%$ & \\
\hline
\end{tabular}

As we can see from the data obtained, a small percentage of students have a high level of motivation to study. But it gradually increases from the $4^{\text {th }}$ year of study, which indicates a more determined motivation for teaching future teachers.

\section{Discussion}

Analysis of scientific and practical training of pre-service teachers enrolled in the Specialty 016: Special Education at the Ternopil Volodymyr Hnatiuk National Pedagogical University showed that work with students in the course of curricular and extracurricular work contribute to the strengthening of the psychological aspect in their professional training: teaching Neuropathology, Fundamentals of Genetics, Correction Preschool Pedagogy, Correction Psychology courses, which requires special combination and justification of teacher's activity with psychodiagnostic, psycho-correction, organization of psychological pieces of training, psychological service, psychological counselling, school of psychologist, group of psychological rehabilitation.

However, neither education, professional selection, nor the creation of a professionally-oriented and psychologically motivated environment was a necessary and sufficient condition for the development of professional teaching. The above do not foster the ability to love children, to be interesting and effective. However, the education creates the preconditions for further development, contribute and help to develop everything that is naturally inherent in a man, is an impetus for the personal development; and mastering a qualitatively new professional level, in turn, promotes spiritual maturity, the pursuit of success, self-improvement and full self-realization. That is why consistent understanding and the use of various scientific approaches to the deployment of the educational process in the context of university education can become a strategy that will allow objective and appropriate development of organizational, methodological, scientific and technological tactics of professional training of future teachers for 
work in the inclusive classroom.

This paragraph should be in your methods section, not here in your discussion of results. In the context of the elaboration of the problems of formation of integrative readiness of future teachers to work in the inclusive classroom, the analysis of the content of the disciplinary-cyclical structure of the curriculum and programmes of the subjects for Specialty 016: Special Education was analysed, covering the teaching of such subjects as Special Psychology; Neurological Bases of Speech Therapy; Anatomy, Physiology, Pathology of Children with the Basics of Valeology; Foreign Language for Professional Purposes; Special Methods of Teaching Calligraphy for Mentally Disabled Children; Inclusive Education, Speech Therapy, Introduction to the Speciality, reflecting training for work with different categories of children, etc.

Based on the results of the analysis of future teacher professional training at the university, it was concluded that future teachers do not have enough hours of independent work and practice. During the study of the curriculum, work, and study programmes we identified duplication of the content of educational subjects, for example, Correction Pedagogy with History (108 hours), Correction Preschool Pedagogy, with a large number of hours spent (180 hours). In particular, the subjects Inclusive Education in the Special Education System (288), Inclusive Education in the Special Education System (54 hours spent) contain the same topics. Besides, the students' independent work is almost unmanaged. The forms and methods of independent work used for the training of future teachers are ineffective because they do not form students' research and cognitive skills, their internal positive motivation, thus leading to the negative results of the formation of future teachers' readiness.

Duplication and unreasonableness of repetition of educational material, "narrowness" of different academic subjects of one cycle leads to confusion of students; the main factor in their educational activities is getting a diploma, which is not an internal motive for success but fulfils an external goal. This was supported by the respondents' answers where thirty-two percent of students stated that they should study individually or vie analysing solving specified pedagogical situations, role-playing, and business games.

The diversity of future professional activity requires a change in the structure and content of future teachers' professional training, which can be accomplished by creating an integrative course that generalizes and deepens students' knowledge, and helps the formation of integrative readiness of future specialists for professional activity. The results of the analysis of the work and study programmes showed that the level of awareness of the students' acquired knowledge in professionally-oriented subjects and the formation of their practical skills were tested only by such types of work as homework and abstract, which is unacceptable for the professional development of future teachers. Besides, the traditional pedagogical technologies and teaching methods used to train future teachers in higher educational institutions were not relevant and productive, since only interactive teaching methods can organically shape the integrative readiness of future teachers: develop their autonomy, responsibility, and communicativeness. In addition, teachers' perceptions of the usefulness of technology to support educational processes determine teachers' intentions to use it (Baydas \& Goktas, 2017).

Teacher's behaviours can have immediate consequences, but it may also give rise to new ideas. Future studies may use statistical analyses that are designed to revise other interacting patterns. Mascareño Lara, Snow, Deunk, and Bosker (2016) propose to combine methods aimed at analysing the content of longer interactive patterns (for example, t-pattern analysis with methods that give more insight into the structure of a creative teacher - studio interaction (Mascareno et al. 2016) This allowed studying the nature of interactions more deeply, for example, whether they are rigid or flexible, and how they relate to other characteristics of the creative process and the creative products that result from these interactions.

In a survey of students-future teachers, it was found that the subject Introduction to the Specialty did not contain clear complete information about this profession for specialists. Students did not realize and understand their major professional functions and responsibilities.

Analysing the scientific and pedagogical literature (Demchenko, 2016; Martynchuk, 2019), it was determined that the profession of a teacher, covering the social phenomena against which the socialization of children takes place, should be inextricably linked with such sciences as pedagogy, ethics, legal science. Besides, such subjects as Psychology, Social Pedagogy, Philosophy, Ethics, and Aesthetics are important for the acquisition of a specialty (Martynchuk, 2019). Future teachers should focus specifically on each individual, so they must study all the psychological and pedagogical aspects of the problems, which will help to work out a constructive solution to them. Therefore, a prerequisite for integrative readiness is the consideration of interdisciplinary relationships, which are based on the combination of knowledge and their complementarity. Effectiveness based on interdisciplinary relationships manifests based on students' ability to carry out the interdisciplinary transfer of knowledge in solving 
cognitive and professional problems, independently solve interdisciplinary problems (see the problem, make a plan of their solution, select the required knowledge on different subjects, summarize them and draw conclusions); motivation of educational and cognitive activity of students; the degree (complexity) of interdisciplinary tasks for students of different years of study and different training; the level of awareness of interdisciplinary relationships in the study of different subjects. Because it is the interdisciplinary relationships that form an integrated picture of the world, it is the foundation of the worldview and a tool for practical and cognitive human activity.

As Alterator and Deed (2013:316) noted, "teaching style that implies flexibility of educational space, choice of student activity, the richness of educational materials, integration of curriculum areas and/or small-group forms of conducting classes" is probably the best form of the formation of readiness for professional activity.

However, since classes are generally understood as a broad construct, they imply the involvement of all participants, where a support system should be used, such as professor working hours or additional courses (Fredricks, Filsecker $\&$ Lawson, 2016). Moreover, visible participation is more likely to occur in small courses as they provide more opportunities for students to engage in behavioural activities, e.g., by doing exercise.

Based on the obtained results, an integrative theoretical and practical course called 'Organization of Inclusive Environment in Educational Institutions' was developed, which includes goals, objectives, integrative skills, content, guidelines for teachers and students, test tasks for testing theoretical productive knowledge. The peculiarity of the course Organization of Inclusive Environment in Educational Institutions is in its structure, namely: the course includes 4 modules, and the calculation of the "weight" of each module is determined by Fibonacci numbers $(\mathrm{F}=0.618 ; \mathrm{F}=1.618$ ), i.e. (Module I is $503 \times 0.23=115.7$ hours $-3.2 \mathrm{Gr}$; Module II is $503 \times 0.3=150.9$ hours $-4.2 \mathrm{Gr}$; Module III is $503 \times 0.34=171.0$ hours $-4,75$ Gr; Module IV is $503 \times 0.13=65.4$ hours $-1.8 \mathrm{Gr}$ ). In addition, training can be presented as three sections ("general" - "special" - "partial"). This is consistent with our vision of the training process and the designed model relies on it. Due to the fact that students who enroll in higher education institutions already have basic knowledge, have the skills and abilities they have acquired in the secondary educational institution, we note that for Speciality 016: Special Education, the "special section" (professional training) with 321.9 hours will be the main; the "general" section (general training) is 115.7 hours; the "partial" section (improvement of professional training) is 65.4 hours.

Analysing professional training of a future teacher, it should be remembered that a student who is characterized by professional orientation, preparing for the highly skilled performance of the functions of a specialist in a certain professional field (Kobriy, 2016), is characterized by the most active development of moral and aesthetic feelings, completion of formation and stabilization of character. To become a professional teacher to work under the conditions of inclusive education in today's economic and social context, and given the qualification requirements for such a specialist, it is important to create during professional training at a higher educational institution and when focusing on the student's age such psychological and pedagogical conditions that will allow us to form an integrative readiness of future specialists for professional activity.

In this way, the simulation method itself will allow an integrated study of the process of formation of future teachers' readiness for work under the conditions of inclusive education, since it will help to see not only the individual elements of this process but also to consider the connections between them. In our study, the model is understood as the image of an ideal teacher who possesses all the necessary qualities and qualities to carry out a professional activity under the conditions of an inclusive educational environment (Kobriy, 2016).

To train a future teacher who can work effectively under the conditions of inclusive education, the theoretical principles of the model of integrative readiness of a future teacher for work under the conditions of inclusive education, who is a competent specialist, mobile and able to solve complex professional problems, are outlined.

The model (see Figure 2) is based on the principles of communicativeness, phasing, the connection of theory with practice, and is based on the systematic, acmeological, personality-oriented, systemic approaches. The model developed is a source of empirical and theoretical knowledge about the possibilities and consequences of introducing the sound experimental methodology of future teachers' professional training to work under the modern conditions of an inclusive educational environment. The model reflects the combination and interconnection of such components as the purpose of professional training of future teachers for work under the conditions of inclusive education, scientific approaches, principles, tools, psychological and pedagogical conditions of learning, the result of students' readiness for professional activity, aimed at achieving the result: formation of integrative readiness of future teachers for work in an inclusive space.

The analysis of the pedagogical literature and research concerning the professionalization of an individual, allowed 
to conditionally distinguish the following main blocks in this model: target, content, and procedural, resultant. The target block of the model is an objective formed by social requests. Therefore, the goal is to build the integrative readiness of future teachers for work under the conditions of inclusive education.

The content and procedural blocks include psychological, pedagogical and methodological conditions, the content of the educational process, forms of education, and basic methods of active and interactive learning. Besides, the emphasis was placed on training future teachers for work in an inclusive space for collaborative learning. As Vangrieken, Meredith, Packer, and Kyndt (2017) note, this type of education requires trust and respect that takes time to develop. Previous research of teacher-student co-learning underlines the importance of teachers' agreement on shared goals and responsibilities and their ability to integrate their differences in teacher thinking (Beaten \& Simons, 2014; Shin, Lee \& McKenna, 2016). All this contributes to the formation of future teachers' readiness for professional activity and the use of basic methods, tools in the educational process with children with special educational problems and to use innovative approach - joint learning - in their future activity.

The resultant block of the model provides for monitoring the effectiveness of future teachers' readiness for professional activity in an inclusive educational environment. Future teachers' readiness for work under the conditions of inclusive education is defined as a complex dynamic system that incorporates interconnected components and provides the internal and behavioural conditions for the teachers' successful fulfilment of their professional responsibilities under the conditions of inclusion.

The goal of any technology adoption model is to anticipate and explain the intentions to use the technology. As for the latter, several large-scale studies in the field of education have shown that teachers tend to have good professional skills (OECD, 2016).

An important aspect in the process of training teachers for work under the conditions of inclusive education is the formation of their professional and personal qualities, productive knowledge, integrative and practical skills.

The study findings agree with Buehl and Beck (2015) who stated the connection between beliefs and pedagogical practice is so complex and interdependent that it is important to first examine the existence of a connection in a particular context before considering which on is the cause and which is the result. Accordingly, within the context of the digital revolution, there is a link between the outlook and pedagogical practices of teachers working in an inclusive space (Shin, Lee, \& McKenna, 2016; Kobriy, 2016). Recently, the study of teachers' beliefs became a priority for researchers of education in Ukraine?. Teachers' beliefs are guided by educational decisions and influence classroom management and serve as an object for understanding classroom events (Prestridge, 2017). In the teachers' activity, ideological conviction determines their socio-moral orientation, which is expressed in social needs, moral and value orientations, and as a sense of social and civic responsibility (Demchenko, 2016).

Based on the didactic chain of the formation of professional readiness, the study focuses on integrative readiness, which is an open, dynamic, synergistic system of purposeful training of future teachers for work in an inclusive classroom, which is included in the educational social environment as a tool for the acquisition of productive knowledge, the formation of integrative skills and abilities. The structure of integrative readiness includes personality orientation (goals, motives, interests, needs); ability to perform their duties (intellectual, emotional, organizational, communicative), professional competences; productive knowledge that the student receives from the information of the environment based on personal prior knowledge, skills, personal and professional qualities, as well as integrative skills that demonstrate the ability of an individual to make independent decisions and appropriate actions in unpredictable new situations (Haiash, 2015).

\section{Conclusion}

One of the main tasks of modern higher pedagogical education is the formation of a new generation teacher who can consistently adjust the education of children under the conditions of inclusive education.

Therefore, this requires changes in the strategy of development of educational systems, in the policy of management of these systems, and finally in the theory and methodology (technologies) of organizing the pedagogical process at higher educational institutions.

The study urged the pedagogical reasonability of forming integrative readiness of future teachers since it is the formation of integrative skills, knowledge, and abilities, as well as the development of personal and professional qualities that allows us to prepare a many-sided individual capable of applying the creative and responsible approach to solving professional problems. The nature, structure, and content of integrative readiness was clarified, which is regarded as "a multidimensional personality trait that includes productive knowledge, integrative skills, abilities, as well as professional and personal qualities". 
Formation of an integrative readiness of future teachers for work under the conditions of educational inclusive space is an important factor in raising their level of education and developing their professional competences. The effectiveness of the organization of corrective developmental and educational work in educational inclusive space largely depends on the quality of training of future specialists and the use of active and interactive training.

There are a number of problems that need to be addressed regarding the development and implementation of the model of the educational environment of higher educational institutions, the interaction of its components, which in aggregate can give a noticeable effect in the development of future teachers' professional training.

\section{Acknowlegements}

We would like to express our sincere gratitude to all students of the Ternopil Volodymyr Hnatiuk National Pedagogical University for Speciality 016: Special Education and to colleagues who assisted in conducting psychological and pedagogical research.

\section{References}

Ahsan, M. T., Deppeler, J. M., \& Sharma, U. (2013). Predicting pre-service teachers' preparedness for inclusive education: Bangladeshi pre-service teachers' attitudes and perceived teaching-efficacy for inclusive education. Cambridge Journal of Education, 43(4), 517-535. https://doi.org/10.10 80/0305764X.2013.834036

Alterator, S., \& Deed, C. (2013) Teacher adaption to open learning spaces. Issues in Educational Research, 23(3), 315-330

Aspelin, J., \& Jonsson, A. (2019). Relational competence in teacher education. Concept analysis and report from a pilot study. Teacher Development, 23(2), 264-283. https://doi.org/10.1080/13664530.2019.1570323

Avidov-Ungar, O., \& Forkosh-Baruch, A. (2018). Professional identity of teacher educators in the digital era in light of the demands of pedagogical innovation. Teaching and Teacher Education, 73(1), 183-191. http://doi.org/10.1016/j.tate.2018.03.017

Baydas, O., \& Goktas, Y. (2017). A model for preservice teachers' intentions to use ICT in future lessons. Interactive Learning Environments, 25(7), 930-945. https://doi.org/10.1080/10494820.2016.1232277

Beaten, M., \& Simons, M. (2014). Student teachers' team teaching: Models, effects, and conditions for implementation. Teaching and Teacher Education, 41, 92-110. https://doi.org/10.1016/j.tate.2014.03.010

Buehl, M., \& Beck, J. (2015). The relationship between teachers' beliefs and teachers' practices. In H. Fives, \& M. G. Gill (Eds.), International handbook of research on teachers' beliefs, 66-84. New York: Routledge.

Chetverikova, N. V. (2017). The actuality of the problem of preservation of the emotional stability of teachers in inclusive education conditions: Modern measurement. Scientific Bulletin of KSU Series Psychological Sciences, 2(3), 107-113.

Dehon, E., Robertson, E., Barnard, M., Gunalda, J., \& Puskarich, M. (2019). Development of clinical teaching evaluation and feedback tool for faculty. The Western Journal of Emergency Medicine, 20(1), 50-57. https://doi.org/10.5811/westjem.2018.11.39987

Demchenko, I. I. (2015). Teacher preparation for work in an inclusive primary school. Uman: FOP Zhovtiy OO.

Demchenko, I. I. (2016). Theoretical and methodical bases of preparation of the future teacher of initial classes for professional activity in the conditions of inclusive education [Unpublished Ph.D. abstract thesis]. Uman State Pedagogical University named after Pavlo Tychyna, Uman, Ukraine.

Fredricks, J., Filsecker, M., \& Lawson, M. (2016). Student engagement, context, and adjustment: Addressing definitional, measurement, and methodological issues. Learning and Instruction, 43, 1-4. https://doi.org/10.1016/j.learninstruc.2016.02.002

Gates, K., \& Liu, S. (2016) Methods for quantifying patterns of dynamic interactions in dyads. Assessment, 23(4), 459-471. https://doi.org/10.1177/1073191116641508

Glaveanu, V., Hanson, H. M., Baer, J., Barbot, B., Clapp, E., Corazza, G., Hennessey, B., Kaufman, J., Lebuda, I., Lubart, T., Montuori, A., Ness, I. J., Plucker, J., Reiter-Palmon, R., Sierra, Z., Simonton, D. K., Neves-Pereira, M. S., \& Sternberg, R. J. (2019). Advancing creativity theory and research: A socio-cultural manifesto. Journal of Creative Behavior. https://doi.org/10.1002/jocb.395

Haiash, O. V. (2015). The cooperation of specialists in inclusive education as the necessary precondition for providing the corrective pedagogical orientation. Current problems of education and upbringing of people with 
special needs, 12(14), 99-113.

Herppich, S., Praetorius, A.-K., Förster, N., Glogger-Frey, I., Karst, K., Leutner, D., Behrmann, L., Böhmer, M., Ufer, S., Klug, J., Hetmanek, A., Ohle, A., Böhmer, I., Karing, C., Kaiser, J., \& Südkamp, A. (2018). Teachers' assessment competence: Integrating knowledge-, process-, and product-oriented approaches into a competence-oriented conceptual model. Teaching and Teacher Education, 76, 181-193. https://doi.org/10.1016/j.tate.2017.12.001

Hobfoll, S., Halbesleben, J., Neveu, J.-P., \& Westman, M. (2018). Conservation of resources in the organizational context: The reality of resources and their consequences. Annual Review of Organizational Psychology and Organizational Behavior, 5(1), 103-128. https://doi.org/10.1146/annurev-orgpsych-032117-104640

Kaufman, J. C., Beghetto, R. A., \& Watson, C. (2016). Creative metacognition and self-ratings of creative performance: A 4-C perspective. Learning and Individual Differences, 51, 394-399. https://doi.org/10.1016/j.lindif.2015.05.004

Kobriy, O. (2016). Professional teacher training modelling in higher educational institutions of Ukraine. Human Studies. Series of Pedagogy, 3(35), 145-152. https://doi.org/10.24919/2313-2094.3/35.93540

Kozlovsky, Yu. M. (2018). Integration processes in vocational education: methodology, theory, methods: monograph. Lviv: Lviv Polytechnic Publishing House.

Kupers, E., Lehmann-Wermser, A., McPherson, G., \& van Geert, P. (2019). Children's creativity: A theoretical framework and systematic review. Review of Educational Research, 89(1), 93-124. https://doi.org/10.3102/0034654318815707

Martynchuk, O. V. (2019). Theory and practice of training specialists in special education for professional activities in an inclusive educational environment [Unpublished doctoral dissertation]. Institute of Special Pedagogy and Psychology named after Mykola Yarmachenko. Kyiv, Ukraine.

Martins, B. A. \& Chacon, M. C. (2020). Teacher Efficacy for Inclusive Practices (TEIP) Scale Validation. Revista Brasileira de Educação Especial, 26(1), 1-16. https://doi.org/10.1590/s1413-65382620000100001

Mascareño Lara, M., Snow, C. E., Deunk, M. I., \& Bosker, R. J. (2016). Language complexity during read-alouds and kindergartners' vocabulary and symbolic understanding. Journal of Applied Developmental Psychology, 44, 39-51. https://doi.org/(...)j.appdev.2016.02.001

Nikolić Vučinić, A., Milić, T., Marić, A., Knezevic, J., Lukačević, J., Klikovac, S., Trailović Šljivančanin, A., Bogićević, I. \& Boskovic, D. (2019). Montenegro Inclusive Education Strategy (2019-2025). UNICEF Country Office in Montenegro \& Ministry of Education of Montenegro. Retrieved from https://www.unicef.org/montenegro/sites/unicef.org.montenegro/files/2019-05/MONTENEGRO_INCLUSIVE_ EDUCATION_STRATEGY_1a-1b-REVISE-6\%20eng.pdf

OECD. (2016). Teachers' ICT and problem-solving skills: Competencies and needs. Education Indicators in Focus, (40). https://doi.org/10.1787/5jm0q1mvzqmq-en

Prestridge, S. (2017). Examining the shaping of teachers' pedagogical orientation for the use of technology. Technology, Pedagogy, and Education, 26(4), 367-381. https://doi.org/10.1080/1475939X.2016.1258369

Rodrigues, I. B., Adachi, J. D., Beattie, K. A., \& MacDermid, J. C. (2017). Development and validation of a new tool to measure the facilitators, barriers, and preferences to exercise in people with osteoporosis. BMC Musculoskelet Disord 18(1), 1-9. https://doi.org/10.1186/s12891-017-1914-5

Skočić Mihić, S., Lončarić, D. \& Bažon, N. (2019). Readiness to teach children with disabilities and gifted children in inclusive classroom settings from the perspective of students enrolled in teacher education study programs. Proceedings for the 13th International Technology, Education and Development Conference, 9086-9092. https://doi.org/10.21125/inted.2019.2258

Shin, M., Lee, H., \& McKenna, J. (2016). Special education and general education preservice teachers' co-teaching experiences: A comparative synthesis of qualitative research. International Journal of Inclusive Education, 20(1), 91-107, https://doi.org/10.1080/13603116.2015.1074732

Suárez-Rodríguez, J., Almerich, G., Orellana, N., \& Díaz-García, I. (2018). A basic model of integration of ICT by teachers: Competence and use. Educational Technology Research \& Development, 66(5), 1165-1187. https://doi.org/10.1007/s11423-018-9591-0

Vangrieken, K., Meredith, C., Packer, T., \& Kyndt, E. (2017). Teacher communities as a context for professional 
development: A systematic review. Teaching and Teacher Education, 61, 47-59. https://doi.org/10.1016/j.tate.2016.10.001 